\title{
Research of the Application of Large Numbers Law on Insurance Risk
}

\author{
Management \\ Shunjie Yuan ${ }^{1}$ \\ ${ }^{1}$ Changzhou University, Changzhou, Jiangsu, 213000
}

KEYWORDS: Large Number; Insurance Risk; Application Case

\begin{abstract}
Risk management is the risk to risk identification, risk estimation, risk evaluation, risk control, decision-making and action to reduce the negative impact of process risk. With the social development and scientific and technological progress, in real life more and more risk factors. People come up with all sorts of ways to cope with risk. But no matter what method, the general principle is a risk management: the minimum cost for maximum protection. Law of large numbers is an important basic law for insurance business. Law of large numbers of homogeneous risk is among a large share of the insurance unit similar to the theory of the firm economies of scale. Economies of scale of production and operational costs apportioned law of large numbers are risk of dispersion. Scale requires the insurance business is to maintain the financial stability of the insurance company an important condition.
\end{abstract}

\section{Introduction}

Probability theory and the law of large numbers for the insurance business provides a theoretical basis the scientific basis of the probability theory and the law of large numbers, in order to ensure the stability of the insurance business should be insured against the risk of having a unit independence and homogeneity.

Underwriting risk unit independence refers to the occurrence of a risk event does not affect the risk of the occurrence of another event. If the underwriting risk is not independent, then one occurrence of the event will inevitably affect the other events, so that the insurer suffered losses caused a chain reaction, causing deviation actual claims expenditure and expectations of compensation expenses plus large, affect the financial stability of insurance.

Underwriting risk homogeneity that each underwriting risk between the rate of dangerous condition, the amount of loss after loss difference should be roughly the same. If the risk is not a homogeneous unit, then once the high loss, will inevitably affect financial stability.

Law of large numbers indicate the number of units of the insurer underwriting risk more losses expected results and the actual results of the loss of the closer. Since the number of units of the insurer underwriting risk is limited, so the insurer can not completely eliminate the risk of loss expected results and the actual results of the loss caused by differences. However, the insurer may minimum number of units underwriting risk based on acceptance of the risk is determined.

\section{Law Of Large Numbers and Financial Stability}

In general, the number and amount of complex stochastic process of the risk of loss of the insurance business are generated by the loss of a decision. But the number of dangerous condition will be affected by the following factors: (l) purely stochastic risk, namely the time the risk, place, the 
result is not easy for insurance companies to fully grasp; factor (2) short-term swings risk that season, climate, and natural disasters will dangerous condition caused by the short-term rate

increases; (3) long-term cyclical risks, such as changes in social, economic, cultural and environmental changes will cause a period of time the dangerous condition of the frequency and amount of loss; change (4) the probability of the dangerous condition of the trend, mainly by risk too concentrated, insurance structure is irrational, the quality of service is not higher cause. The amount of loss is affected by the following factors: (l) inflation; (2) the amount of coverage and the poor, with the representative of the average grade of the general level of business will increase the deviation, affecting the stability of the business; (3) Due to changes lead to insurance underwriting conditions effect change, will cause changes in the amount of compensation; (4) the insurance contract law is not tight, easily lead to error compensation, error compensation, increasing the overall amount of compensation. Due to the above factors, the insurance product design will appear in deviation of the actual risk and expected risk, a measure of this bias is borne by the coefficient of variation. With a loss ratio variation coefficient $\mathrm{K} X$ variance or mean variance with the expected loss $\mathrm{E}(\mathrm{X})$ to measure, assuming that an insurance underwriting of n objects insured, the net rate of

$\mathrm{q}$, the amount of insurance the insurance subject matter are a, due to the loss of the insurance business, subject to the occurrence of two distributions. Therefore, the coefficient of variation:

$$
K=\frac{\mathrm{a} \sqrt{n q(1-q)}}{n a q}=\sqrt{\frac{1}{n}\left(\frac{1}{q}-1\right)} .
$$

In China's insurance industry, the coefficient of variation can be used to reflect the financial stability of the insurance business. Financial stability of the insurance business to understand there are three: a peer relationship between one compensation expenses insurance net premium income and the occurrence; the second is the loss indemnity insurance company accumulated total reserve and risk caused by sudden large peering relationships between; third is the contrast between the insurance company's total deduction of insurance company solvency minimum solvency identified itself with the balance of risks they assume responsibility. Among them, the insurance company's solvency performance compensation reserve containing risk surcharges formed of pure premium, the sum of the total reserves of the three equity capital has been accumulated. Insurance companies bear the risk of liability is mainly reflected in the amount of insurance indemnity risk assumed. Minimum solvency finds itself mainly composed of common equity and a certain amount of total reserves, which amount shall not be less than the national statutory minimum solvency. The insurance company bears the majority of the insured may compensate an insured event occurs or payment liability arising, only the financial stability of their own, have sufficient solvency in order to protect the interests of the insured, to enhance the confidence of policyholders.

In other business activities, the price of goods and services in the cost of production plus a reasonable profit on the basis of the development and is subject to market forces influence the formation. In the insurance industry, insurance products is uncertain due to the loss of the insured event occurred a result, in the current press OK to pay premiums on an uncertain future point in time, for the future financial condition of a contractual guarantee. Insurance companies must policyholders and the public assume fiduciary duty, not only make the insured payment or adequate compensation, and should allow policyholders and other public that the company's continued viability. In an increasingly transparent information disclosure case, the insurance company is required to maintain the necessary volume of business, the use of co-insurance, reinsurance and other means to expand coverage in scale, seeks financial stability of the insurance business. Visible, 
law of large numbers, economies of scale and financial stability of insurance companies has basically the same goal.

\section{Risk Avoidance Strategies}

Risk-averse means to avoid the possibility of loss of initiative. It applies to cope with a high probability of the risk of loss, and to a large extent those losses occurred, the risk of drowning when swimming is taken into account not go swimming. While risk-averse fundamentally eliminate hidden dangers, but this approach clearly has significant limitations. Its limitations in performance, not all risks can be avoided or should be avoided. Such as personal accident, however cautiously, not always completely eliminate such risks. Again, for fear of an accident she refused to ride, although this type of accident risk can thus be completely avoided, but will cause great inconvenience in daily life, in fact, is not feasible. The prevention of risk prevention risk is to take preventive measures to reduce the likelihood and extent of losses incurred losses. Irrigation, construction of shelter forest is a typical example. Prevention of risks related to the current costs and a potential loss of comparative question: If the potential loss is far greater than the cost of taking preventive measures spending on risk prevention methods should be used. In beefing dam, for example, although the high cost of construction, must take into account the huge disaster caused by flooding in the needle, it is extremely necessary.

The risk retention is rational or irrational own initiative to take risks. "Irrational" refers to the loss of luck or the extent of potential losses underestimated and thus exposed to the risk; "rational" means by proper analysis, that potential losses in the affordable range, and his bear all or part of the risk column economical than buying insurance. Therefore, when making "rational" choice, risk retention generally applicable to deal with small occurrence probability, and the low level of risk of loss. Transfer of risk transfer risk is through some kind of arrangement to the risks they face, in whole or in part to the other. Through the transfer of risk is guaranteed, it is the most widely used and most effective risk management tool. Insurance risk management is one of the means of transferring risk. Risk management and insurance, whether in theory or in practice, they are closely linked. From the theoretical point of view the origin, came first, Insurance, after the emergence of risk management. Insurance in the doctrine of the nature of the insurance risk management can not be an important part of the theoretical basis and risk management largely due to the development of insurance in-depth study, however, the subsequent development of risk management are constantly promoting Insurance development theory and practice. From a practical perspective, on the one hand the insurance risk management is one of the most important and most commonly used method; on the other hand by increasing the level of risk identification, can more accurately assess the risk, while the development of risk management to improve the promotion of insurance technical level of play to an important role. To improve risk management, the most important aspect is to raise the level of awareness of risk. Probability theory development, to deepen understanding of risk quantification, risk, improve risk management provides a scientific method. Calculation of net premium prerequisite is to know the probability distribution of potential losses. Practice is based on the theory of probability theory, the use of empirical data to estimate the probability distribution of the accident. Therefore, probability theory is insurance mathematics and physics. "Law of large numbers" is an important law of probability theory, it reveals a pattern: a lot of, under certain conditions, recurring random phenomenon will appear in a certain regularity or stability. For example, we know that throwing a mass distribution of the coin, the probability of its face up to 0.5 , but if you do the experiment 50 times, the number is likely to face up with the expected value 25 times greater odds. In other words, the experiment statistics derived from the frequency (the number 
of face-up divided by the number of experiments) with the objective probability may have a greater gap. But do ten thousand times or more experiments, the statistical probability of frequency and objective difference will be small. As the "law of large numbers" effect, the overall effect of a large number of random factors will inevitably lead to some kind of random events is not dependent on individual results. The law on the insurance business has an important significance. We know that the insurance behavior is dispersed uncertainty together, into a substantially certainty to share losses. According to "law of large numbers," the more homogeneous the subject matter insured, the actual loss results will be closer to the expected loss results. Thus, the premium charged by the insurance company can do with damages and other expenses balance.

\section{Conclusion}

Discussion Based on the above it can be seen, the insurance companies underwriting business volume or scale is an important basis for its stable operation. In addition, the expansion of business scale, the insurance company should pay attention to risk identification and classification, depending on the circumstances of the insured subject matter, design the appropriate insurance policy, by aggregating and technical treatment of homogeneous risks that have different risk insurance shall bear different insurance costs, thus the maximum to avoid adverse selection and promoting the financial stability of the burden of risk equity and insurance company operations.

\section{REFERENCE:}

[1] Adelina Comas-Herrera, Raphael Wittenberg, Linda Pickard. The Long Road to Universalism? Recent Developments in the Financing of Long-term Care in England [J]. Social Policy and Administration, Vol. 44, No 4, 375-391, (2010).

[2] Brown JR, Finkelstein A. The Private Market for Long-Term Care Insurance in the United States: A Review of the Evidence [J]. The Journal of Risk and Insurance, Vol 76, No. 1, 5-29, 2009.

[3] Brown JR, Finkelstein A.. Why Is the Market for Long-Term Care Insurance So Small? [J]. Journal of Public Economics, Vol. 91, No. 10,1967-1991, 2007.

[4] Arntz M, Sacchetto R, et al The German Social Long-Term CareInsurance: Structure and Reform Options [J]. http://ideas.repec.org/p/zbw/zewdip/5467. html. 